American Journal of Applied Sciences 7 (2): 171-177, 2010

ISSN 1546-9239

(C) 2010 Science Publications

\title{
Controlling the Morphology of Nano-Hybrid Materials
}

\author{
Abdullah I. Al Jaafari \\ Department of Physics, College of Science, King Faisal University, \\ P.O. Box 400, Hofuf 31982, Saudi Arabia
}

\begin{abstract}
Problem statement: It is known that layer double hydroxide is one of the nano ordered layered compounds and possesses plate-like morphology if carefully crystallized. Approach: In this study, Co-Sn LDH consisting of divalent and tetravalent cations was prepared with new morphology. XRD patterns of the prepared Co-Sn LDH showed that the interlayer spacing of the LDH was $0.78 \mathrm{~nm}$ and SEM image showed nano-needles structure. Results: By intercalation reaction with monocarboxylic acids at room temperature, XRD patterns indicated that the interlayered spacing increased to 3-4.8 nm and formed organic-inorganic nano-hybrid materials. Also, SEM images showed that the nano-needles structure of Co-Sn LDH changes to plate like-structure. Conclusion: Thermal analyses (TG, DTG and DTA) and Infrared spectrum confirmed the intercalation processes of $\mathrm{n}$-capric acid and n-stearic acid inside Co-Sn LDH and the formation of nano-hybrid materials.
\end{abstract}

Key words: Layer double hydroxide, nano-hybrid materials, nano-layered materials, Co-Sn LDH

\section{INTRODUCTION}

Nano structured inorganic-organic or hybrid organic-inorganic nano composites will contribute to the development of science and technology.

Layered Double-metal Hydroxides (LDHs) are one of the nano ordered layered compounds having ability to intercalate anionic compounds, because LDHs are constituted by infinite sheets of brucite-type material charged positively, where divalent cations are replaced in a fraction of $\mathrm{x}$ by trivalent cations in octahedral coordination. The general formula for these compounds is:

$$
\left(\mathrm{M} 2_{1-\mathrm{x}} \mathrm{M} 3_{\mathrm{x}}(\mathrm{OH})_{2}\right)^{\mathrm{x}+} .\left(\mathrm{A}^{-}\right)_{\mathrm{x}} \cdot \mathrm{n} \mathrm{H}_{2} \mathrm{O}
$$

Where:

M2, M3 = Divalent and trivalent cations, respectively

A $=$ Represents interlayer anions that restore the electrical neutrality of the compound

The distance between two adjacent layers depends mainly on the nature of the interlayer species and their electrostatic interaction with the main layers

Layered double-metal hydroxides are receiving increasing interest in recent years owing to their potential applications in various technologies such as catalysis (Bhattacharjee et al., 2004; Choudary et al., 2004; Li et al., 2005; Zhang et al., 2004; Climent et al., 2004; Perez et al., 2004; Davis and Derouane, 1991; Narayanan and Krishna, 1998) adsorption
(Intissar et al., 2004; Zhang and Reardon, 2003), anion exchanges (Dutta and Puri, 1989), medicine (Nakayama et al., 2003; Khan et al., 2001; Ambrogi et al., 2001), photo applications (Guo et al., 2004), electro applications (Mousty et al., 1994; Therias and Mousty, 1995; Liao and Ye, 2004) and nano-composites (Lin et al., 2005; Wang and Zhang, 2004 ; Camino et al., 2001). A widespread application of LDHs is anticipated by the reason of the pronounced anion-exchange capacity toward inorganic and organic anions.

The present study examines the possibility of preparation of new morphology of layered structure. This new structure contains $\mathrm{Co}^{2+}$ and $\mathrm{Sn}^{4+}$ cations in host layers and cyanate and carbonate anions as the guests. Also, nano-hybrid materials were prepared through the intercalation reactions of this layered structure with organic materials. The effect of orientation of guest inside the lamellar region of layered structure on the morphology of LDH structure was clarified.

\section{MATERIALS AND METHODS}

The Co-Sn LDH was prepared through reaction of cobalt and tin salts in presence of urea solution. A solution of cobalt nitrate and tin chloride $(0.047$ moles) were mixed under vigorous stirring and heated for long time with controlling of $\mathrm{PH}$. The percentage of tin is $22 \mathrm{~mole} \%$. After filtration and washing in distilled water, the products were dried under vacuum at room temperature. Also, Co-Al LDH was prepared by the 
same method for comparison. The LDH $(0.24 \mathrm{~g})$ was mixed with the solution of organic acid sodium salt (0.002 moles) under $\mathrm{Ar}$ atmosphere with ultrasonic treatment and stirred $60^{\circ} \mathrm{C}$ for $12 \mathrm{~h}$. After filtration and washing, the samples were dried under vacuum at room temperature.

The EDS measurements were carried out with JEOL JED-2140. Powder X-Ray Diffraction (XRD) spectra were recorded on Rigaku, RINT 2200. Thermal analyses (TG, DTG and DTA) of powdered samples up to $800^{\circ} \mathrm{C}$ were carried out at a heating rate of $10^{\circ} \mathrm{C} / \mathrm{min}$ in flow of nitrogen using a Seiko SSC 5200 apparatus. FT-IR spectra ( $\mathrm{KBr}$ disc method) were recorded on a Horiba FT-720. Scanning Electron Microscopy (SEM) was performed with JEOL: JSM-6330F.

\section{RESULTS AND DISCUSSION}

Preparation of Nano-layered material with new morphology: Natural samples of layered double hydroxide (pyroaurite) exhibit plate-like morphology with plates being millimeters in thickness and centimeter in width (Bruun Hansen and Koch, 1995). Also, it is known that hydrotalcite crystals possess hexagonal platy morphology if carefully crystallized (Ogawa and Asai, 2000). A similar morphology is observed for Co-Al LDH with dimension of the plates in the order of few micrometers in width and $100 \mathrm{~nm}$ in thickness as shown in Fig. 1a. The individual plates of Co-Al LDH are flat and the edges of the plates appear rounded and hexagonal in agreement with the sharp edges observed on natural crystals of layered double hydroxides. In the case of preparation of Co-Sn LDH, SEM image showed nano-needles structure as shown in Fig. 1b. This considers a new morphology for layered structure.

However, the measured XRD pattern of Co-Sn LDH fits well to layered structure with no evidence for other phases. The peaks exhibit some common features of layered materials such as narrow, symmetric, strong peaks at low $2 \theta$ values and weaker, less symmetric lines at high $2 \theta$ values. The X-ray diffraction of Co-Sn LDH (Fig. 2b) showed the basal peaks of planes hkl (003), (006) and (009) agreeing with the basal peaks of layered structure of Co-Al LDH. The good agreement between the values corresponding to successive diffractions by basal planes, i.e., $\mathrm{d}(003)=2 \mathrm{~d}(006)=$ $3 \mathrm{~d}(009)$ for Co-Sn LDH, reveals highly packed stacks of brucite-like layers ordered along axis c. Dimension c is calculated as three times the spacing for planes (003), i.e., $2.34 \mathrm{~nm}$. The c dimension is very close to that reported for natural and synthetic hydrotalcite, $2.31 \mathrm{~nm}$ (Intissar et al., 2002; Leroux et al., 2001). The XRD patterns of Co-Sn LDH have the main peak at $0.78 \mathrm{~nm}$ which corresponded to interlayer spacing of the $\mathrm{LDH}$ as shown in Fig. 2. This value is related to the thickness of the brucite-like layers ( $0.48 \mathrm{~nm}$ for hydrotalcite), as well as the size of the anion (and, in some cases, its orientation) and the number of water molecules existing in the interlayer. The peaks of layered structure disappeared by the calcination at $500^{\circ} \mathrm{C}$ and appearance of new peaks at high $2 \theta$ values as shown in Fig. 2c indicates the formation of metal oxides.

Energy Dispersive X-ray Spectrometer (EDS) analysis provides local information of the concentrations of different elements in the LDH. Cobalt, tin, carbon, oxygen and nitrogen are clearly identified in one spot on The insertion of cyanate anion (NCO-) into Co-Sn LDH is very easily demonstrated by the strong IR absorption peak at $2221 \mathrm{~cm}^{-1}$ that assigned to symmetrical stretching vibration mode of $\mathrm{CNO}$ as shown in Fig. 4. As can be noted in the Fig. 4,

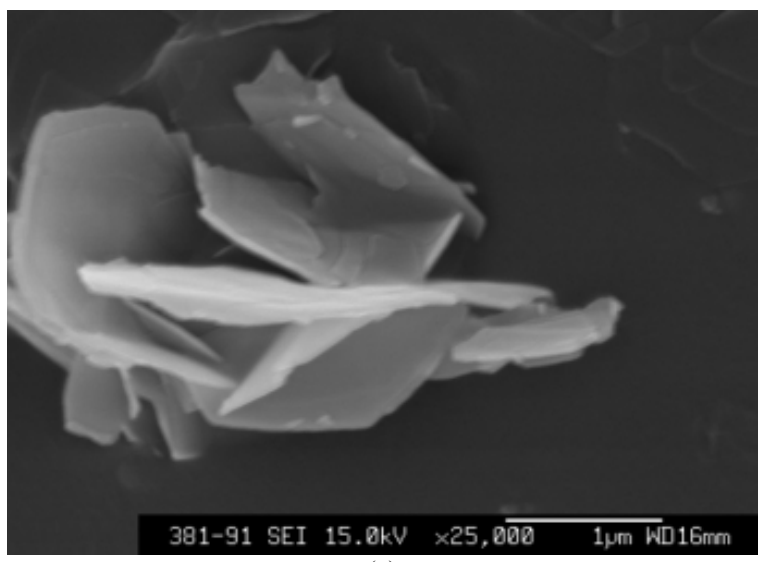

(a)

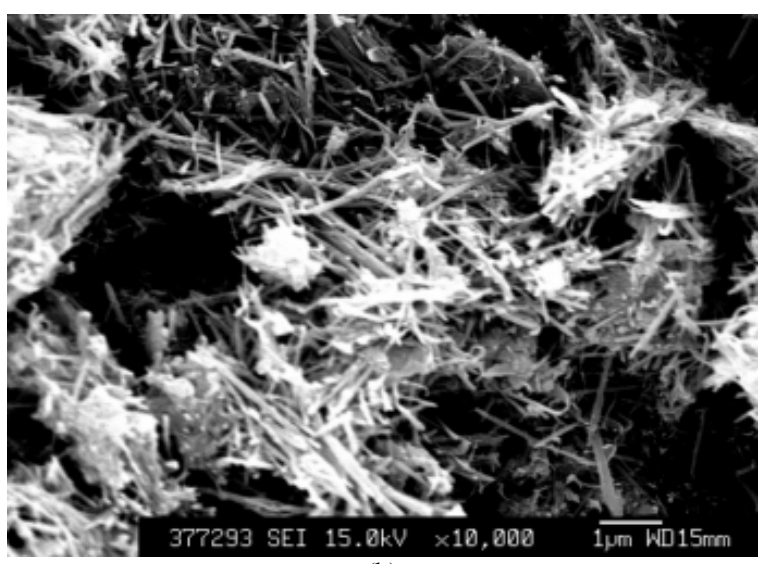

(b)

Fig. 1: SEM images of (a) Co-Al LDH and (b) Co-Sn LDH 


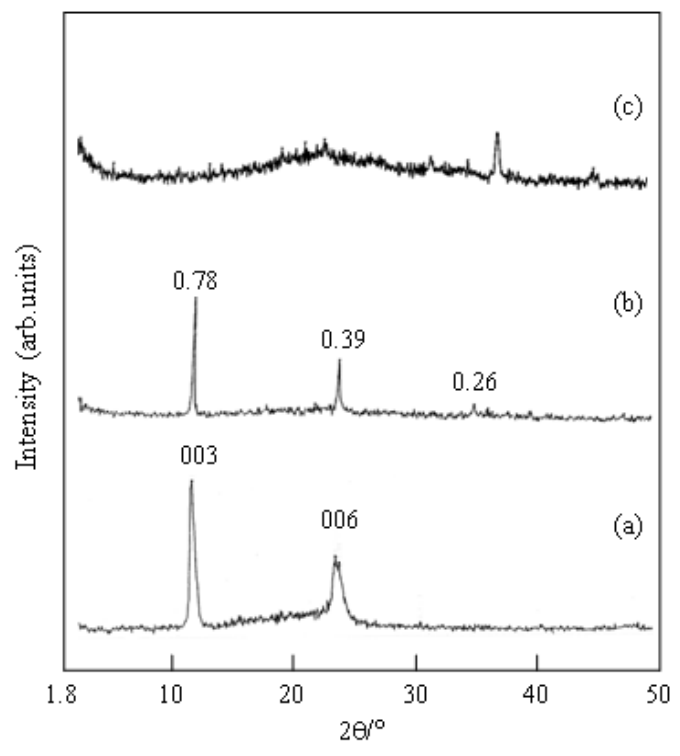

Fig. 2: X-ray diffraction patterns of (a) Co-Al LDH; (b) $\mathrm{Co}-\mathrm{Sn} \mathrm{LDH}$; (c) $\mathrm{Co}-\mathrm{Sn} \mathrm{LDH}$ with calcinations at $500^{\circ} \mathrm{C}$

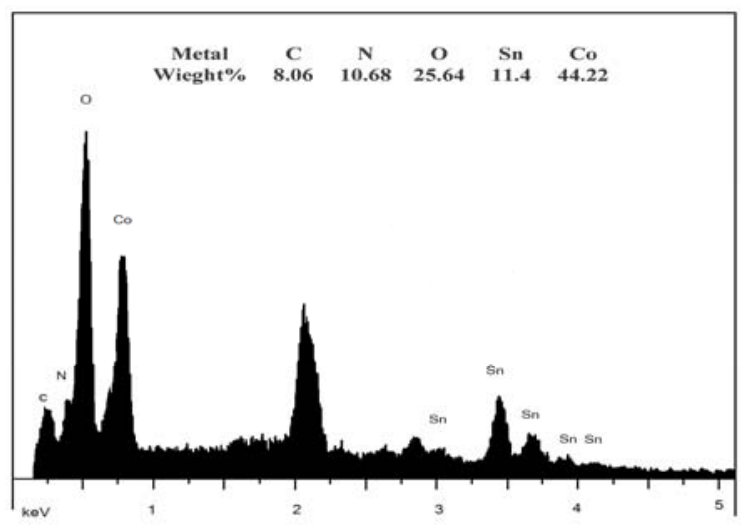

Fig. 3: EDS spectra of Co-Sn LDH

the carbonate anion into the interlayer space are also confirmed by clear absorption peaks at 1383 and $1508 \mathrm{~cm}^{-1}$ (Nakamoto, 2009; Miyata, 1975) and supported from the chemical composition. The stretching vibration of hydroxyl group $v_{\mathrm{OH}}$ is clearly observed at around $3500 \mathrm{~cm}^{-1}$ (Vaccari, 1999; Labajos et al., 1992). These IR spectra results indicate that the prepared sample Co-Sn LDH has similar structure with Co-Al LDH structure and it was confirmed the presence of carbonate anions and cyanate anions in addition to water molecules inside the interlayer space of Co-Sn LDH while in case of Co-Al $\mathrm{LDH}$, it showed carbonate anions.

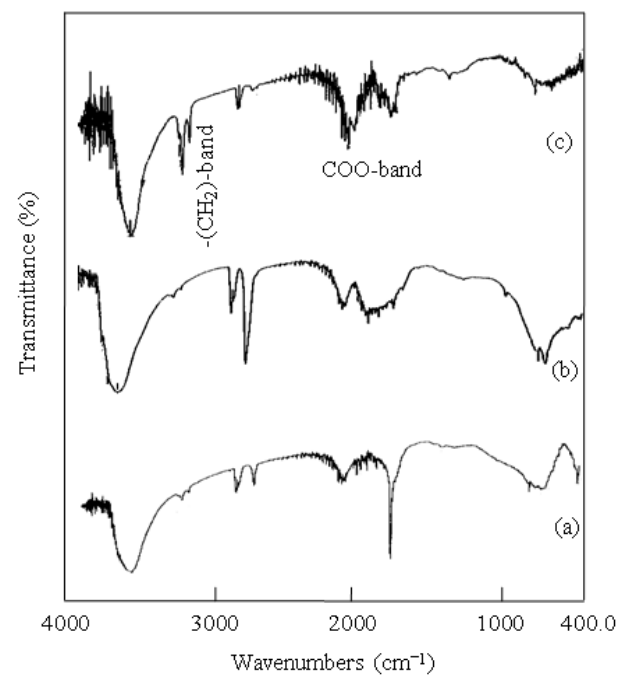

Fig. 4: IR spectra of (a) Co-Al LDH; (b) Co-Sn LDH; (c) Co-Sn LDH after intercalation with n-capric acid

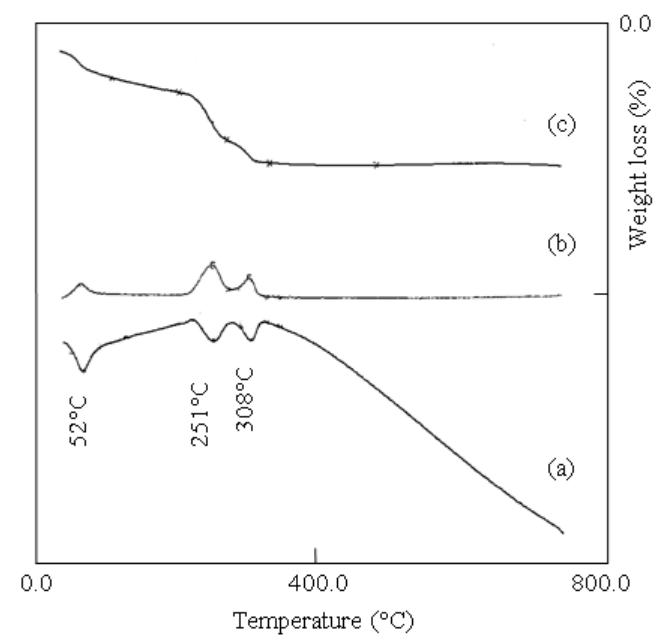

Fig. 5: Thermal analysis of Co-Sn LDH in nitrogen gas: (a) TG; (b) DTG; (c) DTA

Thermal characteristics of the Co-Sn LDH in nitrogen gas were determined by TG, DTG and DTA as shown in Fig. 5. Major losses of weight occur mainly in four steps. The TG diagram showed that the first weight loss up to $90^{\circ} \mathrm{C}$ is $4.5 \%$ and the second weight loss up to $200^{\circ} \mathrm{C}$ is $8 \%$. This agrees with the amount of water, which previously mentioned in the chemical formula of Co-Sn LDH. The main weight loss occurs from $200-336^{\circ} \mathrm{C}$ in two steps. The first step corresponded to the decomposition of cyanate anion and the second step due to the decomposition of carbonate anions and dehydroxylation process. These steps confirmed from DTG and DTA diagrams. DTA diagram show three endothermic peaks as shown in Fig. $5 \mathrm{a}$. 


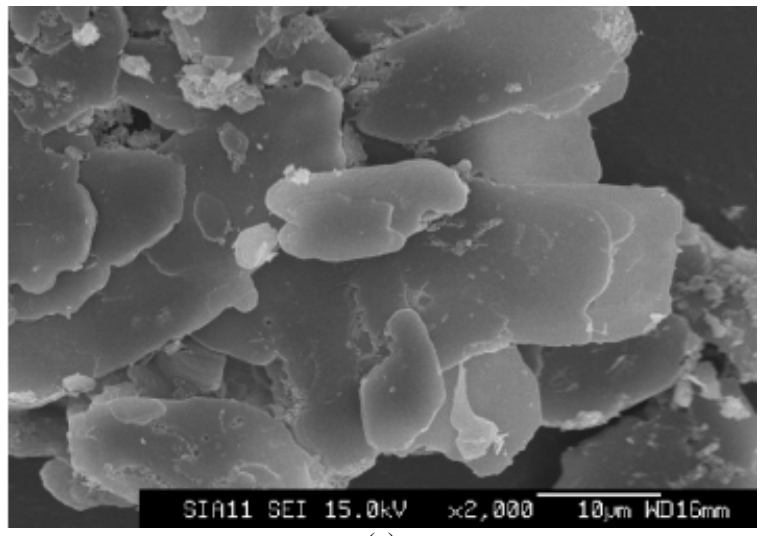

(a)

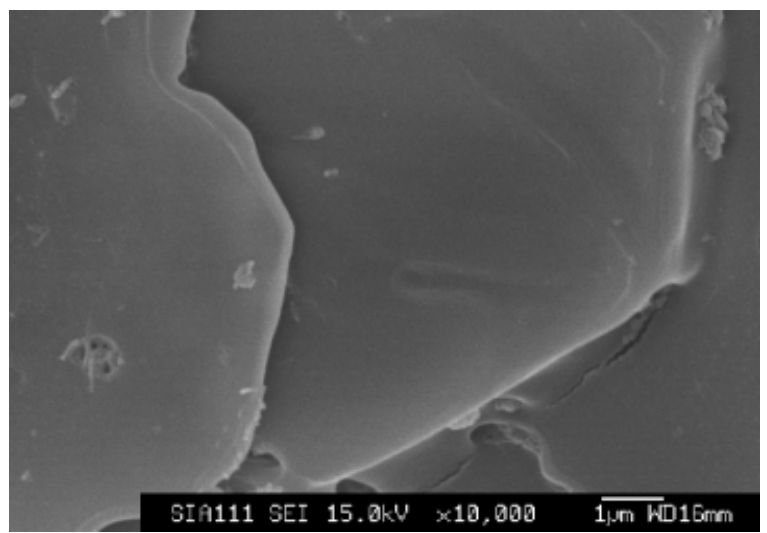

(b)

Fig. 6: SEM images of Co-Sn LDH after intercalation with n-capric acid (a) at low magnification and (b) at high magnification

The first peak at around $52^{\circ} \mathrm{C}$ corresponds to the desorption of surface water, the second at $250^{\circ} \mathrm{C}$ corresponds to the decomposition of cyanate anions and the third peak at $308^{\circ} \mathrm{C}$ corresponds to the decomposition of carbonate and dehydroxylation of layers Co-Sn LDH as shown in Fig. 3.

Preparation of Nano-hybrid materials: The reaction products of Co-Sn LDH with n-capric acid show a clear plate-like morphology indicating that the needle morphology could convert to plate like morphology. Also, the average size of the organic compounds containing crystallites is much larger than that for the samples before intercalation reactions as shown in Fig. 6.

The XRD patterns showed that new peaks were observed at low $2 \theta$ indicating interlayer spacing $3.0 \mathrm{~nm}$ after the reaction of $\mathrm{Co}-\mathrm{Sn} \mathrm{LDH}$ with n-capric acid as shown in Fig. 7a. Also, by the treatment of Co-Sn LDH with longer organic acid, stearic acid, new peaks were observed at lower $2 \theta$ indicating interlayer spacing 4.8 $\mathrm{nm}$ as shown in Fig. $7 \mathrm{~b}$.

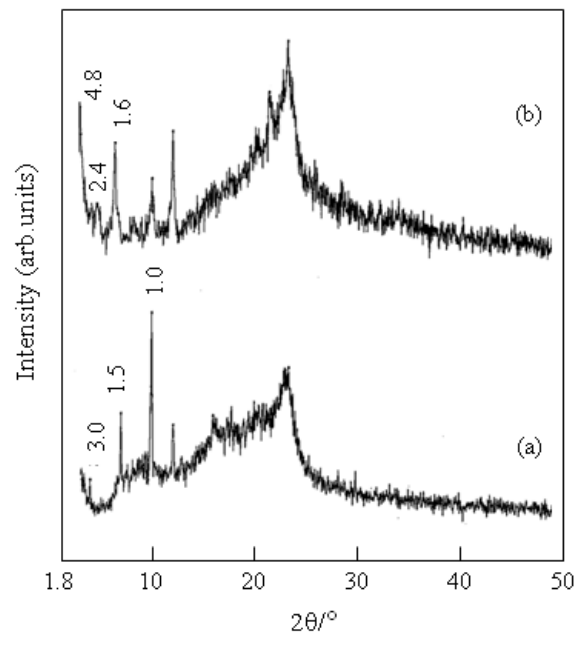

Fig. 7: X-ray diffraction patterns of Co-Sn LDH after intercalation with (a) n-capric acid $\left(\mathrm{CH}_{3}\left(\mathrm{CH}_{2}\right)_{8} \mathrm{COOH}\right)$ and (b) stearic acid $\left(\mathrm{CH}_{3}\left(\mathrm{CH}_{2}\right)_{16} \mathrm{COOH}\right)$

Also, the existence of organic compound into CoSn LDH after intercalation reactions was confirmed by the results of IR spectroscopy as shown in Fig. 4c. In the IR spectrum of the reaction products of Co-Sn LDH with straight chain of aliphatic acid such as n-capric acid, the carbon-hydrogen stretch absorption at near $2900 \mathrm{~cm}^{-1}$ and the carbon-hydrogen bending band at $1470 \mathrm{~cm}^{-1}$ were observed as shown in Fig. 4c. Also, the new peaks at near 1540 and $1400 \mathrm{~cm}^{-1}$ appeared. The absorption at $1540 \mathrm{~cm}^{-1}$ is assigned to the symmetric stretching vibration of carboxylate and the absorption at $1400 \mathrm{~cm}^{-1}$ is assigned to the asymmetric stretching vibration of carboxylate.

In addition, the absorption band of hydroxyl group did not disappear while the absorption bands of cyanate and carbonate anions disappeared. TG curves of ncapric acid and the reaction product of Co-Sn LDH with n-capric acid sodium salt are shown in Fig. 8. Figure 8 indicated that decomposition temperature of ncapric acid Shifted to higher temperatures by intercalation. These results suggested occurrence of the intercalation reaction of organic acids with Co-Sn LDH.

Mechanism of controllable morphologies of LDHs: According to decomposition of urea, the earlier investigators (Shaw and Bordeaux, 1955) indicated that the ammonium cyanate is an intermediate with decomposition of urea and the complete decomposition of urea produced carbonate anions as shown in Eq. 1 and 2:

$\mathrm{Urea} \rightarrow \mathrm{NH}_{4}^{+} \mathrm{CNO}^{-}$

$\mathrm{NH}_{4}^{+} \mathrm{CNO}^{-}+2 \mathrm{H}_{2} \mathrm{O}+2 \mathrm{H}^{+} \rightarrow \mathrm{NH}_{4}^{+}+\mathrm{H}_{2} \mathrm{CO}_{3}$ 
Am. J. Applied Sci., 7 (2): 171-177, 2010

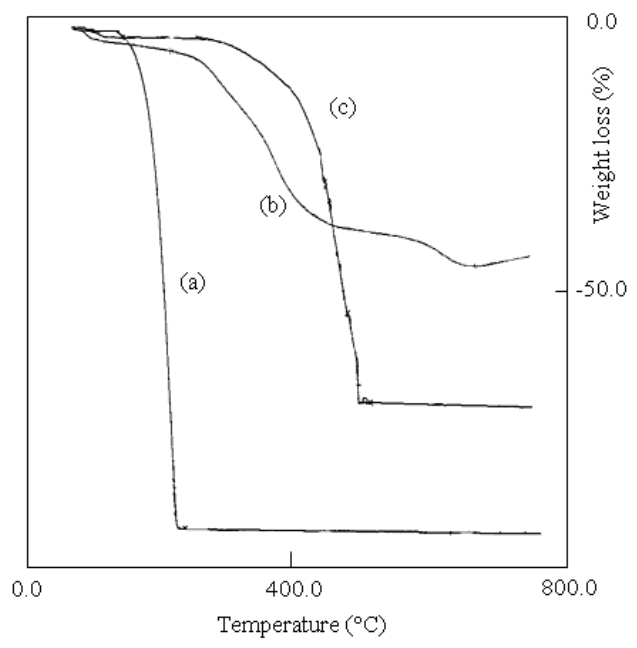

Fig. 8: Thermal Gravimetric (TG) of (a) n-capric acid only, (b) the reaction product of Co-Sn LDH with n-capric acid and (c) n-capric acid sodium salt only

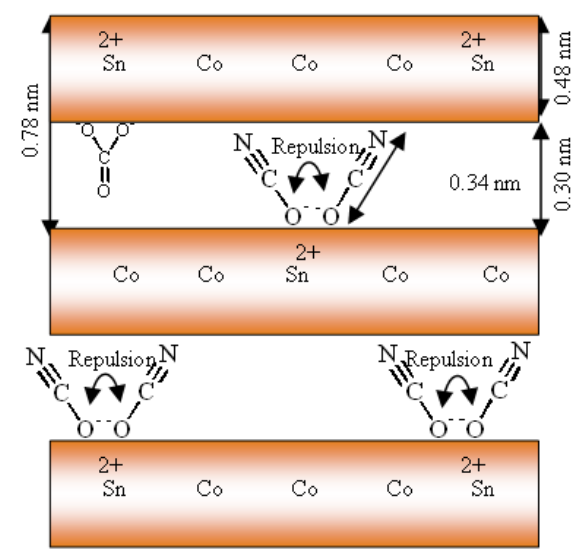

Fig. 9: Schematic representation of Co-Sn LDH for nano-needle structure

Therefore, the decomposition of urea considers as a source for cyanate and carbonate anions. The powder XRD patterns are not sufficiently high quality to allow us to carry out structure determination. However, by interlayer spacing and the size of the guest ions, orientation of guest ions was considered. From known layer thickness, $0.48 \mathrm{~nm}$, the interlayer spacing available for the anion was calculated as $0.30 \mathrm{~nm}$. By comparison with the size of cyanate anion, $0.34 \mathrm{~nm}$ and in presence of carbonate anions, there is a competition process occurred between both anions. This leads to needles structure. Where the presence of carbonate anions in the interlayer spacing will push two cyanate anions $(-1)$ to attack tin cation $(+2)$ from one side.

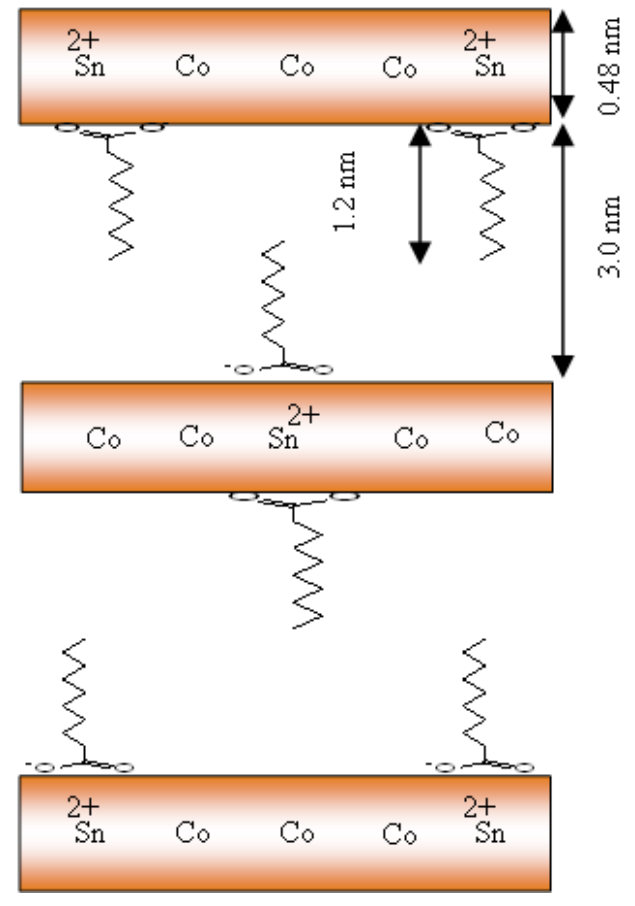

Fig. 10: Schematic representation of nano-hybrids CoSn LDH with plate-like structure

So, this leads to stearic repulsion between bulky cyanide groups, which cause curling of the layers giving needles structure as shown in Fig. 9.

After intercalation reactions with long chains of fatty acids, anions exchanges were occurred and the organic species inserted among the layers into lamellar region instead of carbonate and cyanate anions. Because of the long chains of organic species and disappearance of carbonate and cyanate anions, needles structure changed to plate-like structure as shown in Fig. 10.

\section{CONCLUSION}

In this study, the results presented in this work show that the formation of layered double hydroxides is not limited to plate-like morphology, although these are the only morphology reported by many researchers. SEM images showed that layered materials can exist as a needles and plate-like structure. Also, we compared among the morphologies of Co-Al and Co-Sn LDHs. Anion-exchange reactions were successful in replacing inorganic anions with organic anions into Co-Sn LDH and changing its morphology. Furthermore, we discussed the formation mechanisms of different morphologies of LDHs. 


\section{REFERENCES}

Ambrogi, V., G. Fardella, G. Grandolini and L. Perioli, 2001. Intercalation compounds of hydrotalcite-like anionic clays with antiinflammatory agents-I. Intercalation and in vitro release of ibuprofen. Int. J. Pharm., 220: 23-32. DOI: 10.1016/S03785173(01)00629-9

Bhattacharjee, S., T.J. Dines and J.A. Anderson, 2004. Synthesis and application of layered double hydroxide-hosted catalysts for stereoselective epoxidation using molecular oxygen or air. J. Catal., 225: 398-407. DOI: 10.1016/j.jcat.2004.04.008

Bruun Hansen, H.C. and C.B. Koch, 1995. Synthesis and characterization of pyroaurite. Applied Clay Sci., 10: 5-19. DOI: 10.1016/0169-1317(95)00014-U

Camino, G., A. Maffezzoli, M. Braglia, M. de Lazzaro and M. Zammarano, 2001. Effect of hydroxides and hydroxycarbonate structure on fire retardant effectiveness and mechanical properties in ethylene-vinyl acetate copolymer. Polymer Degradat. Stability, 74: 457-464. DOI: 10.1016/S0141-3910(01)00167-7

Choudary, B.M., T. Someshwar, M.L. Kantam and C.V. Reddy, 2004. Molybdate-exchanged Mg-AlLDH catalyst: An eco-compatible route for the synthesis of $\beta$-bromostyrenes in aqueous medium. Catal. Commun., 5: 215-219. DOI: 10.1016/j.catcom.2004.02.003

Climent, M.J., A. Corma, S. Iborra and A. Velty, 2004. Activated hydrotalcites as catalysts for the synthesis of chalcones of pharmaceutical interest. J. Catal., 221: 474-482. DOI: 10.1016/j.jcat.2003.09.012

Davis, R.J. and E.G. Derouane, 1991. A non-porous supported-platinum catalyst for aromatization of nhexane. Nature, 349: 313-315. DOI: 10.1038/349313a0

Dutta, P.K. and M. Puri, 1989. Anion exchange in lithium aluminate hydroxides. J. Phys. Chem., 93: 376-381. DOI: 10.1021/j100338a072

Guo, S., D. Li, W. Zhang, M. Pu, D.G. Evans and X. Duan, 2004. Preparation of an anionic azo pigmentpillared layered double hydroxide and the thermoand photostability of the resulting intercalated material. J. Solid State Chem., 177: 4597-4604. DOI: $10.1016 /$ j.jssc.2004.09.028

Intissar, M., R. Segni, C. Payen, J. Besse and F. Leroux, 2002. Trivalent cation substitution effect into layered double hydroxides Co2FeyAl1$\mathrm{y}(\mathrm{OH}) 6 \mathrm{Cl} \cdot \mathrm{nH} 2 \mathrm{O}$ : Study of the local order-Ionic conductivity and magnetic properties. J. Solid State Chem., 167: 10.1006/jssc.2002.9669
Intissar, M., S. Holler, F. Malherbe, J.P. Besse and F. Leroux, 2004. Incorporation of Ti4+ into layered double hydroxide sheets? The response by X-ray diffraction and absorption study. J. Phys. Chem. Solids, 65: 453-457. DOI: 10.1016/j.jpcs.2003.08.030

Khan, A.I., L. Lei, A.J. Norquist and D. O’Hare, 2001. Intercalation and controlled release of pharmaceutically active compounds from a layered double hydroxide. Chem. Commun., 1: 2342-2343. DOI: 10.1039/b106465g

Labajos, F.M., V. Rives and M.A. Ulibarri, 1992. Effect of hydrothermal and thermal treatments on the physicochemical properties of $\mathrm{Mg}-\mathrm{Al}$ hydrotalcite-like materials. J. Mater. Sci., 27: 1546-1552. DOI: $10.1007 /$ BF00542916

Leroux, F., E.M. Moujahid, C. Taviot-Gueho and J.P. Besse, 2001. Effect of layer charge modification for CoAl layered double hydroxides: Study by X-ray absorption spectroscopy. Solid State Sci., 3: 81-92. DOI: 10.1016/S1293-2558(00)01119-5

Li, F., Q. Tan, D.G. Evans, X. Duan, 2005. Synthesis of carbon nanotubes using a novel catalyst derived from hydrotalcite-like Co-Al layered double hydroxide precursor. Catal. Lett., 99: 151-156. DOI: $10.1007 / \mathrm{s} 10562-005-2107-7$

Liao, C.S. and W.B. Ye, 2004. Structure and conductive properties of poly(ethylene oxide)/layered double hydroxide nanocomposite polymer electrolytes. Electrochimica Acta, 49: 4993-4998. DOI: 10.1016/j.electacta.2004.06.018

Lin, Y.J., D.Q. Li, D.G. Evans and X. Duan, 2005. Modulating effect of Mg-Al-CO3 layered double hydroxides on the thermal stability of PVC resin. Polymer Degradat. Stability, 88: 286-293. DOI: $10.1016 /$ j.polymdegradstab.2004.11.007

Mousty, C., S. Therias, C. Forano and J.P. Besse, 1994. Anion-exchanging clay-modified electrodes: Synthetic layered double hydroxides intercalated with electroactive organic anions. J. Electroanal. Chem., 374: 63-69. DOI: 10.1016/00220728(94)03346-3

Miyata, S., 1975. The syntheses of hydrotalcite-like compounds and their structures and physicochemical properties $\mathrm{I}$ : The systems $\mathrm{Mg}^{2+}-\mathrm{Al}^{3+}$ $\mathrm{NO}_{3}^{-}, \mathrm{Mg}^{2+}-\mathrm{Al}^{3+}-\mathrm{Cl}^{-}, \mathrm{Mg}^{2+}-\mathrm{Al}^{3+}-\mathrm{ClO}_{4}^{-}, \mathrm{Ni}^{2+}-\mathrm{Al}^{3+}-$ $\mathrm{Cl}^{-}$and $\mathrm{Zn}^{2+}-\mathrm{Al}^{3+}-\mathrm{Cl}^{-}$. Clays Clay Minerals, 23: 369-375. DOI: 10.1346/CCMN.1975.0230508

Nakamoto, K., 2009. Infrared and Raman Spectra of Inorganic and Coordination Compounds, Part A, Theory and Applications in Inorganic Chemistry. 6th Edn., Wiley-Interscience, ISBN-10: 0471743399, pp: 432. 
Nakayama, H., K. Takeshita and M. Tsuhako, 2003. Preparation of 1-hydroxyethylidene-1,1diphosphonic acid-intercalated layered double hydroxide and its physicochemical properties. J. Pharm. Sci., 92: 2419-2426. DOI: 10.1002/jps. 10498

Narayanan, S. and K. Krishna, 1998. Hydrotalcitesupported palladium catalysts Part I: Preparation, characterization of hydrotalcites and palladium on uncalcined hydrotalcites for $\mathrm{CO}$ chemisorption and phenol hydrogenation. Applied Catal. A: Gen., 174: 221-229. DOI: 10.1016/S0926860X(98)00190-2

Ogawa, M. and S. Asai, 2000. hydrothermal synthesis of layered double hydroxide-deoxycholate intercalation compounds. Chem. Mater., 12: 3253-3255. DOI: $10.1021 / \mathrm{cm} 000455 \mathrm{n}$

Perez, C.N., C.A. Perez, C.A. Henriques and J.L.F. Monteiro, 2004. Hydrotalcites as precursors for $\mathrm{Mg}, \mathrm{Al}-$ mixed oxides used as catalysts on the aldol condensation of citral with acetone. Applied Catal. A: Gen., 272: 229-240. DOI: 10.1016/j.apcata.2004.05.045

Shaw, W.H.R. and J.J. Bordeaux, 1955. the decomposition of urea in aqueous media. J. Am. Chem. Soc., 77: 4729-4733. DOI: 10.1021/ja01623a011

Therias, S. and C. Mousty, 1995. Electrodes modified with synthetic anionic clays. Applied Clay Sci., 10: 147-162. DOI: 10.1016/0169-1317(95)00013-T
Vaccari, A., 1999. Clays and catalysis: A promising future. Applied Clay Sci., 14: 161-198. DOI: 10.1016/S0169-1317(98)00058-1

Wang, X. and Q. Zhang, 2004. Effect of hydrotalcite on the thermal stability, mechanical properties, rheology and flame retardance of poly(vinyl chloride). Polymer Int., 53: 698-707. DOI: 10.1002/pi.1482

Zhang, M. and E.J. Reardon, 2003. Removal of B, Cr, $\mathrm{Mo}$, and Se from wastewater by incorporation into hydrocalumite and ettringite. Environ. Sci. Technol., 37: 2947-2952. DOI: 10.1021/es020969i

Zhang, L., F. Li, D.G. Evans and X. Duan, 2004. Structure and surface characteristics of $\mathrm{Cu}$-based composite metal oxides derived from layered double hydroxides. Mater. Chem. Phys., 87: 402-410. DOI: 10.1016/j.matchemphys.2004.06.010 